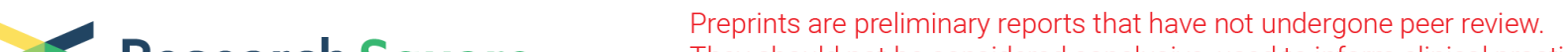 $\begin{array}{ll}\text { Research Square } & \begin{array}{l}\text { They should not be considered conclusive, used to inform clinical practice, } \\ \text { or referenced by the media as validated information. }\end{array}\end{array}$
}

\section{A Tool (SPOLERC) to Guide the Evaluation of Phosphorus Leaching for Agricultural Soil by Using Soil Phosphorus Leaching Change Point in the Lake Xingkai Basin, China}

\section{Zijian Xie}

Chinese Research Academy of Environmental Sciences

Fan Zhang

Chinese Research Academy of Environmental Sciences

Chun Ye ( $\nabla$ yechun@craes.org.cn )

Chinese Research Academy of Environmental Sciences

https://orcid.org/0000-0001-5926-2708

Hao Wang

Chinese Research Academy of Environmental Sciences

\section{Weiwei Wei}

Chinese Research Academy of Environmental Sciences

Chunhua Li

Chinese Research Academy of Environmental Sciences

\section{Xiaogang Shi}

University of Glasgow

\section{Research Article}

Keywords: SPOLERC, Phosphorus leaching, Xingkailake Basin, Single factor index method

Posted Date: September 8th, 2021

DOl: https://doi.org/10.21203/rs.3.rs-861177/v1

License: (c) (i) This work is licensed under a Creative Commons Attribution 4.0 International License. Read Full License 


\section{Abstract}

\section{Background}

As the key factor of soil P leaching risk assessment, soil P leaching change point (CP) has been widely reported. However, there was no report have clearly described the calculation method of soil P leaching $\mathrm{CP}$ value and its automation calculation. Additionally, there was no effective risk grading method performed on the classification of soil $\mathrm{P}$ leaching evaluation.

Results

This study has optimized the calculation process of soil P leaching CP value under two different models. Subsequently, based on the Python programming language, a computation tool named SPOLERC (Soil Phosphorus Leaching Risk Calculator) was developed for soil P leaching risk assessment. SPOLERC not only embedded the calculation process of soil P leaching CP value, but also introduced the single factor index (SFI) method to grade the soil P leaching risk level. Considering the relationships between soil Olsen-P and leachable $P$ fitted by using SPOLERC in paddy land soils and arid agricultural land soils in the Lake Xingkai basin, results have shown that there is a good linear fitting relationship between soil Olsen-P and leachable P; and the CP values were 59.63 and 35.35 mg Olsen- $\mathrm{P} \mathrm{kg}^{-1}$ in paddy land soils and arid agricultural land soils, respectively. Additionally, $32.7 \%, 21.8 \%$, and $3.64 \%$ of arid agricultural soil samples are at low risk, medium risk, and high risk of $\mathrm{P}$ leaching, and $40.6 \%$ of paddy land soil samples are at low risk.

\section{Conclusions}

The SPOLERC can accurately fit the split-line model relationship between soil Olsen-P and leachable $\mathrm{P}$, and greatly improve the calculating efficiency for soil P leaching CP value. Additionally, the obtained CP value can be used for soil $P$ leaching risk assessment, which can provide support for the quantitative study of soil P leaching loss and the control technology of soil P leaching loss.

\section{Background}

Phosphorus $(P)$ is an essential element for crop growth and one of the main controlling factors leading to water eutrophication. Soil $\mathrm{P}$ losses, on the one hand, will degenerate soil quality and result in an unbalance of soil nutrients ( $L i$ et al., 2019). On the other hand, when P enter waters and exceed a certain concentration $(0.03 \mathrm{mg} / \mathrm{L}$ in inorganic $P$ and $0.1 \mathrm{mg} / \mathrm{L}$ in total $\mathrm{P})$, the water quality will deteriorate, even contribute to the outbreak of water bloom (King et al., 2015; Li et al., 2015; Li et al., 2019). Originally, most studies have concentrated on $\mathrm{P}$ losses by soil erosion and surface runoff, as the subsurface $\mathrm{P}$ losses were considered negligible. In the last two decades, soil $\mathrm{P}$ losses by subsurface pathway, such as $\mathrm{P}$ leaching, have been attracting substantial attention, and the subsurface pathways in some events were reported to play a dominated role in P loss from agricultural land to water (Heckrath et al., 1995; Ulen et al., 2007; Li et al., 2015; Jalali and Jalali et al., 2017; Xie et al., 2019). Consequently, it is of great 
significance to conduct soil $\mathrm{P}$ leaching loss in farmland soil, which will improve $\mathrm{P}$ management in arable soil and water ecosystem.

$\mathrm{CaCl}_{2}-\mathrm{P}$, soil leachable $\mathrm{P}$ extracted by $0.01 \mathrm{M} \mathrm{CaCl}_{2}$ solution, has a significant positive linear correlation with soil P leachates, and effectively used to indicate the complexity of soil P entering soil solution or surface runoff (Heckrath et al., 1995; Li et al., 2015; Xie et al., 2019). Soil P leaching Change point (CP) is estimated by using the split-line model to fit the relationship between soil leachable $\mathrm{P}$ and soil Olsen-P, and often used to evaluate P leaching risk in topsoil (Heckrath et al., 1995; Zhao et al., 2014; Jalali and Jalali, 2017). Recently, Xie et al. (2019) proposed the cascade extraction method and verified that the soil leachable $\mathrm{P}$ and $\mathrm{CP}$ value could use to evaluate $\mathrm{P}$ leaching risk in soil profiles. Although the research on soil $\mathrm{P}$ leaching risk evaluation has been continuously performing, the calculating process of soil $\mathrm{P}$ leaching $\mathrm{CP}$ value is not clearly described in the previous literature.

The $\mathrm{CP}$ value often used to evaluate the soil $\mathrm{P}$ leaching risk. Generally, when soil Olsen-P was higher than the $C P$ value, significant $P$ losses through leaching should occur; otherwise, there was no $P$ leaching risk (Li et al., 2015; Xie et al., 2019). This method is easy to operate, but failed to classified the low-risk area and high-risk area, which is not conducive to the hierarchical management of soil $\mathrm{P}$ leaching risk areas. The single factor index (SFI) method is an effective method to classify the risk level (Li et al., 2008). The higher the evaluation index value is, the more serious the risk level is. Therefore, it may be a meaningful attempt to grade the degree of soil $\mathrm{P}$ leaching risk and clarify the severity of $\mathrm{P}$ leaching loss in different sampling sites by using the SFI method.

Python is a programming language with characteristics of open source, free of charge, high execution efficiency and strong portability (Bernardi and Swanson, 2021). Through the custom function provided by Python, soil P leaching CP value can be automatically and quickly fitted, which is beneficial for improving the accuracy and efficiency of CP value's fitting process. However, there is no research performing on the fitting of soil $\mathrm{P}$ leaching $\mathrm{CP}$ value based on Python programming language.

The Lake Xingkai basin is located in the southeast of Jixi city, Heilongjiang Province. It is a border lake between China and Russia. Over the past 20 years, the water quality in the Lake Xingkai basin decreased from level $\otimes\left(0.025 \mathrm{mg} \mathrm{L}^{-1}\right)$ to level $\mathbb{Q}\left(0.1 \mathrm{mg} \mathrm{L}^{-1}\right)$, the increase of total $P$ concentration is the main reason for the continuously deterioration of water quality (Ji et al., 2013; Yuan et al., 2018). There are nearly $3300 \mathrm{~km}^{2}$ of paddy and dry land, and the main crops planted include corn, soybean, rice and vegetables (Yuan et al., 2018). It is estimated that about $5.4 \mathrm{t} \mathrm{a}^{-1}$ of total P flows into the Lake Xingkai Basin, and the planting pollution contributed to more than $80 \%$ of water pollution in the Lake Xingkai basin (Piao and Wang, 2011; Wan et al., 2013). Thus, it is of practical significance to carry out soil $P$ leaching risk evaluation in the Lake Xingkai Basin.

The aims of this study were (i) to optimize the calculation process of soil $\mathrm{P}$ leaching $\mathrm{CP}$ value; (ii) to combine the CP value and the SFI method for the hierarchical management of soil P leaching risk level; 
(iii) to develop a software for the calculating of soil P leaching CP value and its risk evaluation; (iv) to assess the $\mathrm{P}$ leaching risk of farmland soils under different land uses in the Lake Xingkai Basin.

\section{Materials And Methods}

The soil phosphorus leaching risk calculator (SPOLERC) has been developed by using Python. The installation package, programming language, and the instruction book of the SPOLERC are described in the attachment. The operation interface of the SPOLERC was shown in Fig. 1. Overall, The SPOLERC is constitute of four parts: data collection, data preview, CP value calculation, and the risk evaluation. It is worth mentioning that the results evaluated by the SPOLERC software has finally been combined with the ArcGIS tool for the analysis of soil P leaching risk spatial distribution. By using the case study in the Lake Xingkai Basin, the principle and details of SPOLERC are described as follows:

\subsection{Data collection}

Data collection is the prerequisite of soil $\mathrm{P}$ leaching risk evaluation. It constitutes of the selection of the study area, the collection and analysis of soil samples. The main data used for soil P leaching risk evaluation are soil Olsen-P and leachable P.

\subsubsection{Selection of the study area}

The northwest part of the Lake Xingkai basin was selected as the study area. A border area of $62.5 \mathrm{~km}^{2}$ among the towns of Xingkaihu and Chengzihe was chosen for sampling (Fig. 2.). The soil within the study area was classified as black soil. This region has a temperate monsoon climate zone. The annual mean temperature is $3{ }^{\circ} \mathrm{C}$, with an average annual temperature of $-18{ }^{\circ} \mathrm{C}$ in January and $21^{\circ} \mathrm{C}$ in July; the annual mean rainfall is $654 \mathrm{~mm}$, and almost $70 \%$ of the mean annual rainfall is concentrated in summer (Liu et al, 2019). Six decades ago, the large-scale wetland reclamation has led to farmland becoming the dominant land use type in the watershed (Yuan et al, 2018). Land uses mainly include arid agricultural land $\left(35.3 \mathrm{~km}^{2}, 56.4 \%\right)$, paddy land $\left(23.2 \mathrm{~km}^{2}, 37.2 \%\right)$, and villages ( $\left.4.0 \mathrm{~km}^{2}, 6.4 \%\right)$. Within arid agricultural land, the main vegetation species were corn (Zea mays L.) and soybean (Glycine max (Linn.) Merr.), while the main crop in the paddy land was paddy rice (Oryza sativa L.). It is worth mentioned that some vegetable plots around the household residential land. This area is difficult to separate from the village, and the vegetable types included chinese cabbage (Brassica pekinensis (Lour.) Rupr.), carrot (Raphanus sativus L.). Chemical fertilizers were applied in the arid agricultural land and paddy land, with an amount of 56.2-168.7 $\mathrm{kg} \mathrm{N} \mathrm{ha}^{-1} \mathrm{yr}^{-1}, 30.0-90.0 \mathrm{ka} \mathrm{P} \mathrm{ha}^{-1} \mathrm{yr}^{-1}$, and 25.9-77.6 $\mathrm{kg} \mathrm{K}$ $\mathrm{ha}^{-1} \mathrm{yr}^{-1}$. Organic fertilizers (animal manure and farmyard manure) were used in the vegetable planting area.

\subsubsection{Collection of soil samples}


A total of 87 soil samples were collected in this area from sample sites (55 in arid agricultural land, and 32 in paddy land) at 0-20 cm soil depth in October 2020 (Fig. 2.). Soil was collected in the field and subsequently transported to the laboratory, where the roots and debris were removed. Samples were air dried at room temperature and then 2-mm sieved for determining soil Olsen $\mathrm{P}$, and leachable $\mathrm{P}$.

\subsubsection{Soil analysis and data preparation}

Olsen $\mathrm{P}$ was extracted with $0.5 \mathrm{M} \mathrm{NaHCO}_{3}(\mathrm{pH}=8.5)$ solution with a soil/solution ratio of 1:20 (Lu et al., 1999). Leachable $P$ was extracted with $0.01 \mathrm{M} \mathrm{CaCl}_{2}$ solution with a soil/solution ratio of $1: 5$ (Li et al, 2015). Then, $P$ in the extract solution was determined using the molybdenum blue method (Murphy and Riley, 1962). Subsequently, the data of soil Olsen-P and leachable $P$ have been saved in Excel documents for analysis; the data example is shown in "input_file.xIs".

\subsection{Data preview and soil P leaching change point calculation}

The purpose of data preview is able to select the appropriate calculation model for soil P leaching CP value. The selection of calculation model depends on the linear relationship between soil Olsen-P and leachable $P$. If there were two distinct linear relationships, and the linear correlation between soil Olsen-P and leachable P after the CP was significant $(p<0.05)$, the CP value was estimated based on the intersection of the two linear equations (Li et al, 2015; Jalali and Jalali, 2017; Xie et al, 2019), and the data distribution sample of scatter diagram is shown in Fig S.1. In this case, the "M1 Change point" function in the SPOLERC was used to calculated the soil P leaching CP value.

Model 1 is the most common calculation model of soil $\mathrm{P}$ leaching $\mathrm{CP}$ value. The calculation process of soil $P$ leaching $C P$ value has been shown in Fig. 3. The two-segment linear relationships were defined by Eqs. (1) and (2):

$y_{1}=a_{1} x+b_{1}, R_{1}$-squre, $x<C P(1)$

$y_{2}=a_{2} x+b_{2}, R_{2}$-squre, $x \geq C P(2)$

Firstly, the soil Olsen-P values should be ordered from the smallest to the largest Before the formal calculation, and the R-square of two-segment unitary linear combination was calculated by iterative method (Fig. 3.). Subsequently, the method of least-squares regression was used to determine the optimal linear relationship of the two-segment linear model, and evaluated the parameters $\left(a_{1}, b_{1}, R_{1}\right.$ squre, $a_{2}, b_{2}$ and $R_{2}$-squre) in the equations (Fig. 3.). Finally, the CP value was determined by using the optimal linear relationship between the two two-segment linear model. Mostly, CP value indicates the critical level for soil Olsen-P (Fig. 3.).

However, if there was only one linear relationship between soil Olsen-P and leachable $P$, and the linear correlation between soil Olsen-P and soil leachable P before the CP did not exist. Then, the CP value would estimate based on the intersection of the $\mathrm{X}$ axis and another linear significant relationship between 
soil Olsen-P (high-value area) and soil leachable $\mathrm{P}(p<0.05)$ (Xie et al, 2021), and the data distribution sample of scatter diagram is shown in Fig S.2. In this case, the "M2 Change point" function in the SPOLERC was used to calculated the P leaching CP value.

\subsection{Soil P leaching risk evaluation}

The SFI method was introduced to grade soil P leaching risk level. The higher the evaluation index value is, the more serious the $\mathrm{P}$ leaching risk is. The calculation formula of SFI method is:

$P_{i}=C_{i} / C P(3)$

$P_{i}$ represents the evaluation index of soil $\mathrm{P}$ leaching; $C_{i}$ represents soil Olsen-P content; $C P$ represents soil $P$ leaching change point. The risk rate of soil phosphorus leaching is shown in Table 1. Noticeably, if the $\mathrm{CP}$ value was calculated by using "M1 Change Point", the "M1 Risk Evaluation" function in the SPOLERC was used to evaluate the risk probability. Similarly, if the CP value was calculated by using "M2 Change Point", the "M2 Risk Evaluation" function in the SPOLERC was used to evaluate the risk probability.

Table 1

The classification of soil $P$ leaching risk

\begin{tabular}{|c|c|c|c|c|}
\hline$P_{i}$ & $P_{i} \leq 1$ & $1 \mathbb{Q} P_{i} \leq 2$ & $2 \bigotimes P_{i} \leq 3$ & $P_{i} \rrbracket 3$ \\
\hline Ris & No risk & Low risk & isk & High risk \\
\hline
\end{tabular}

Table 2

The classification of soil $\mathrm{P}$ leaching risk in arid agricultural soils and paddy land soils (mg Olsen- $\mathrm{P} \mathrm{kg}^{-1}$ )

\begin{tabular}{|lllll|}
\hline Risk level & No risk & Low risk & Medium risk & High risk \\
\hline Arid agricultural soils & $\leq 59.63$ & $59.63 \sim 119.26$ & $119.26 \sim 178.89$ & $\otimes 178.89$ \\
\hline Paddy land soils & $\leq 35.35$ & $35.35 \sim 70.70$ & $70.70 \sim 106.05$ & $\otimes 106.05$ \\
\hline
\end{tabular}

Based on the soil P leaching CP value and the evaluation index of soil P leaching measured by SFI method. Subsequently, ArcGIS 10.2 was used to analyze the data by normal distribution, and an optimal model for spatial analysis was chosen.

\section{Results}

\subsection{The change point for $P$ leaching in agricultural soils}

The scatter distribution figure between soil Olsen $\mathrm{P}$ and leachable $\mathrm{P}$ in arid agricultural soils and paddy land soils were presented by SPOLERC, respectively, and the result is shown in Fig. S3. Whether in Figures S3a or S3b, it seems have two different ranges of value distribution, which were similar to some previous 
graphs presented by Li et al. (2015) and Xie et al. (2019). Consequently, "Model 1" was selected to calculate the $\mathrm{CP}$ value of soil $\mathrm{P}$ leaching.

As shown in Fig. 4., significant linear, positive relationships between Olsen-P and leachable $P$ in agricultural soils were calculated by SPOLERC under different land use after the CP value. According to the statistical analysis of 55 arid agricultural soil samples, the relationships between soil Olsen-P and leachable $\mathrm{P}$ were classified into two straight lines with very different slopes (Fig. 4a.). There was a specific point (Change point) between the two lines, which was considered to constitute the soil $\mathrm{P}$ leaching $\mathrm{CP}$ value. The fitting equations between soil Olsen-P and leachable $\mathrm{P}$ in arid agricultural soils calculated by SPOLERC are as follows:

$y=0.0073 x+0.01$, R-square $=0.0969, n=16(4)$

$y=0.0751 x-4.0369$, R-square $=0.865, n=39(5)$

The Eqs. (4) and Eqs. (5) indicated the leaner relationships between soil Olsen-P and leachable P in lowvalue area and high-value area, respectively. With regard to Eqs. (4) and Eqs. (5), the intersection of the two lines (CP value) was found at $59.63 \mathrm{mg}$ Olsen- $\mathrm{P} \mathrm{kg}^{-1}$, and the corresponding leachable $\mathrm{P}$ was 0.44 $\mathrm{mg} \mathrm{kg}^{-1}$.

Subsequently, 32 paddy soil samples have been analyzed by using the same procedure described above, the $\mathrm{CP}$ value of soil $\mathrm{P}$ leaching was $35.35 \mathrm{mg}$ Olsen- $\mathrm{P} \mathrm{kg}^{-1}$, and the corresponding soil leachable $\mathrm{P}$ was $0.02 \mathrm{mg} \mathrm{kg}^{-1}$. The $\mathrm{CP}$ value of soil $\mathrm{P}$ leaching in present arid agricultural soils was slightly higher than that in paddy land soil.

\subsection{Risk evaluation and distribution of $P$ leaching in agricultural soils}

SFI method was used to evaluated soil $P$ leaching risk probabilities. As for the agricultural soil samples analyzed by SPOLERC (Fig. 5a.), $41.8 \%$ of soil samples is not at risk of P leaching, while $32.7 \%, 21.8$, and $3.64 \%$ of soil samples are at low risk, medium risk, and high risk of P leaching, respectively. Likewise, the paddy land soil samples were analyzed by SPOLERC (Fig. 5b.); results have demonstrated that $59.4 \%$ of soil samples is not at risk of $P$ leaching, while $40.6 \%$ of soil samples are at low risk. It is worth mentioning that no soil is at middle risk or high risk in paddy land soil. Therefore, the risk probability of $\mathrm{P}$ leaching from arid agricultural soils was higher than that from paddy soils.

Subsequently, an ordinary kriging method was used to assess the $\mathrm{P}$ leaching probability distribution according to the land uses (Fig. 6). The low-risk areas of soil P leaching were mainly distributed in the east and north part of the study area. In addition, the medium risk and high-risk areas were dotted in the west of the study area. Land use and crop types could be one of the reasons for the present spatial distribution pattern. The paddy soils distributed in the east part of the study area and the arid agricultural 
soils in the west part planted with corn and soybean were at low risk, while the arid agricultural soils around the villages planted vegetables have a medium or high risk of $\mathrm{P}$ leaching.

\section{Discussion}

The research on soil $\mathrm{P}$ leaching $\mathrm{CP}$ value has been continuously performed for nearly 20 years. Heckrath et al. (1995) has originally found the linear split-line model between soil Olsen-P and the dissolved reactive $P(D R P)$ in drainage water according a continuous wheat experiment in Broadbalk. If soil Olsen- $P$ in plow layer exceeded a certain value (60 mg Olsen- $\mathrm{P} \mathrm{kg}^{-1}$ ); then, $\mathrm{P}$ losses, particularly the DRP, in the drainage water were much more closely related to Olsen-P than commonly suggested, the certain value of Olsen-P was defined as the CP value (Heckrath et al., 1995). Subsequently, Heskrath and Brookes (2000) confirmed that the $\mathrm{CP}$ value evaluated on Broadbalk could occur on other soils. Additionally, they found that the special linear relationship between soil Olsen-P and DRP in drainage water could also find between soil Olsen-P and $0.01 \mathrm{M}-\mathrm{CaCl}_{2}$-extractable $\mathrm{P}$, and the $\mathrm{CP}$ value for soil $\mathrm{P}$ leaching risk assessment have been predicted (Heskrath and Brookes, 2000). Consequently, $0.01 \mathrm{M}-\mathrm{CaCl}_{2}$-extractable $\mathrm{P}$ has been developed as an indicator for the risk of soil $\mathrm{P}$ leaching. Afterwards, the $\mathrm{CP}$ value was applied to the risk assessment of soil P leaching around the world, and some new progresses have been made. Bai et al (2013) raised the $\mathrm{CP}$ values for crop yield, soil fertility and environmental safety by fitting the split-line model between soil Olsen-P and the crop yields, soil Olsen-P and total P (TP), respectively. Li et al (2015) proved that the $\mathrm{CP}$ value could evaluate from the relationship between $0.01 \mathrm{M} \mathrm{CaCl}_{2}$ - extractable organic $\mathrm{P}$ and soil available P. Xie et al (2019) proposed that the CP value could be used for the risk evaluation of soil $\mathrm{P}$ leaching in deep soil profile measured by a cascade extraction method. However, the previous haven't clearly described the calculating process of soil P leaching CP value. No study has conducted on the improving of soil $\mathrm{P}$ leaching $\mathrm{CP}$ value calculation method and its automation. This study has not only optimized the calculation process of soil P leaching CP value, but also developed an automatic tool (SPOLERC) for the calculation of soil P leaching CP value and its risk evaluation. On the one hand, the SPOLERC has embedded the calculation process of soil P leaching CP value under two different models; on the other hand, it introduced the SFI method to evaluate the soil P leaching risk level. Results have demonstrated that the SPOLERC can accurately and quickly measure the soil P leaching CP value, and evaluate the soil $\mathrm{P}$ leaching risk levels. Therefore, the SPOLERC is practical for the calculation of soil $\mathrm{P}$ leaching $\mathrm{CP}$ value calculation and the evaluation of soil $\mathrm{P}$ leaching risk.

Soil types, Soil land use, $\mathrm{pH}$ value and SOM content can pose a significant influence on soil $\mathrm{P}$ leaching change point. Hesketh and Brookes (2000) have founded that the CP value in the agricultural soils of UK were varied from 10-110 mg Olsen- $\mathrm{P} \mathrm{kg}^{-1}$. Similarly, Zhao et al. (2007) have founded that the changepoint in 13 types of Chinese agricultural soils were ranged from 30 to $160 \mathrm{mg}$ Olsen-P kg-1. The CP value in agricultural soil was slightly higher than that of forest soil, Li et al (2015) and Xie et al (2019) studied that the CP value in agricultural soils were 85 and $30.2 \mathrm{mg} \mathrm{kg}^{-1}$, which is higher than that value in forest soils (46 and $20.0 \mathrm{mg} \mathrm{kg}^{-1}$, respectively). In addition, there was a special relationship between soil CP value and $\mathrm{pH}$. When soil $\mathrm{pH}<6.0$, the $\mathrm{CP}$ value increased with soil $\mathrm{pH}$, but in the $\mathrm{pH}>6.0$ soils, the $\mathrm{CP}$ 
value decreased with soil pH (Zhao et al, 2007). It is worth mentioning that biochar application can significantly lifted the CP value. According to the indoor incubation experiment, Zhao et al (2014) demonstrated that biochar application can improve soil CP value from 48.65 and $71.25 \mathrm{mg}$ Olsen-P kg-1 to 185.07 and $98.66 \mathrm{mg}$ Olsen- $\mathrm{P} \mathrm{kg}^{-1}$, respectively. Xie et al (2021) has confirmed this result through a field trials (33.52 mg Olsen- $\mathrm{P} \mathrm{kg}^{-1}$ vs $25.86 \mathrm{mg}$ Olsen- $\mathrm{P} \mathrm{kg}^{-1}$ ). In the present investigation, the $\mathrm{CP}$ value measured in arid agricultural soils was higher than that value in the paddy land soils $\left(59.63 \mathrm{mg} \mathrm{P} \mathrm{kg}^{-1}\right.$ vs. $35.35 \mathrm{mg} \mathrm{P} \mathrm{kg}^{-1}$ ). And these values were slightly lower than that reported for soils in Broadbulk (60 $\mathrm{mg} \mathrm{P} \mathrm{kg}{ }^{-1}$ ) and much higher than that reported for fluvisol soils in Chaobaihe basin (30.4 $44.4 \mathrm{mg} \mathrm{P}$ $\mathrm{kg}^{-1}$ ) (Hesketh and Brookes, 2000; Xie et al, 2019; Xie et al, 2021). The difference of soil types and land use may be the main reason for this result.

Soil P leaching risk in arid agricultural land soils was higher than that of paddy land soils. The difference of fertilizer application rate may be the main reason contribute to the difference of soil P leaching risk. The main type of crops grown in arid agricultural land included vegetable, corn, and soybean. Vegetable planting is an important use in arid agricultural land.

\section{Conclusion}

This study optimized the calculation process of soil P leaching change point (CP) value and developed an automatic tool-SPOLERC for the calculation of soil P leaching CP value by using Python programming language. Similarly, the SFI method was introduced to the SPOLERC for grading soil P leaching risk level. Subsequently, the SPOLERC was used to evaluate the agricultural soil P leaching risk in the Lake Xingkai basin. Resulted have showed that there is a good linear relationship between soil Olsen-P and soil leachable $\mathrm{P}$, and the soil $\mathrm{P}$ leaching $\mathrm{CP}$ value and its risk level can be accurately calculated. The CP values calculated in arid agricultural land soils and paddy land soils of the Lake Xingkai Basin were 59.63 and $35.35 \mathrm{mg}$ Olsen- $\mathrm{P} \mathrm{kg}^{-1}$ respectively. In addition, almost $32.7 \%, 21.8 \%$, and $3.64 \%$ of arid agricultural soil samples are at low risk of soil $\mathrm{P}$ leaching, medium risk, and high risk of soil $\mathrm{P}$ leaching, while $40.6 \%$ of paddy land soil samples are at low risk. The risk of $P$ leaching in the soils of arid agricultural land was higher than in those of paddy land soils. The medium risk and high-risk areas were dotted in the west of the study area. Land use and crop types could be one of the reasons that contributed to the present spatial distribution pattern.

\section{Declarations}

\section{Ethics approval and consent to participate}

Not applicable

\section{Consent for publication}

Not applicable 
Availability of data and materials

The datasets used and/or analyzed during the current study are available from the corresponding author on reasonable request.

\section{Competing interests}

The authors declare that they have no competing interests.

\section{Funding}

This project was funded by the National Key Research and Development Project of China (the Demonstration of non-point source pollution control technology and application in river basin) and the Lake Xingkai Basin Ecological Environment Survey Project.

\section{Author's contributions}

Zijian Xie (first author): Conceptualization, Methodology, Formal analysis, Investigation, Writing - Original Draft; Fan Zhang (Co-first author): Conceptualization, Methodology, Formal analysis, Investigation; Chun Ye: Validation, Resources, Writing - Review \& Editing, Supervision; Hao Wang: Formal analysis, Investigation; Weiwei Wei: Investigation; Chunhua Li: Validation, Resources, Writing - Review \& Editing, Supervision; Xiaogang Shi: Conceptualization, Writing - Review \& Editing.

\section{Acknowledgements}

Not applicable

\section{Author details}

a National Engineering Laboratory for Lake Pollution Control and Ecological Restoration, Chinese Research Academy of Environmental Sciences, Beijing 100012, China

b School of Interdisciplinary Studies, University of Glasgow, Dumfries, Scotland, DG1 4ZL, United Kingdom

\section{References}

Bai, Z., Li, H., Yang, X., Zhou, B., Shi, X., Wang, B., Li, D., Shen, J., Chen, Q., Qin, W., Oenema, O., \& Zhang, F. (2013). The critical soil P levels for crop yield, soil fertility and environmental safety in different soil types. Plant and Soil, 372(1-2), 27-37. https://doi.org/10.1007/s11104-013-1696-y

Bernardi, A., \& Swanson, J. M. J. (2021). CycFlowDec: A Python module for decomposing flow networks using simple cycles. SoftwareX, 14, 100676. https://doi.org/10.1016/j.softx.2021.100676 
Heckrath, G., Brookes, P. C., Poulton, P. R., \& Goulding, K. W. T. (1995). Phosphorus Leaching from Soils Containing Different Phosphorus Concentrations in the Broadbalk Experiment. Journal of Environmental Quality, 24(5), 904-910. https://doi.org/10.2134/jeq1995.00472425002400050018x

Hesketh, N., and P.C. Brookes. (2000). Development of an Indicator for Risk of Phosphorus Leaching. J. Environ. Qual. 29:105-110. doi:10.2134/jeq2000.00472425002900010013x

Jalali, M., \& Jalali, M. (2017). Assessment risk of phosphorus leaching from calcareous soils using soil test phosphorus. Chemosphere, 171(January), 106-117.

https://doi.org/10.1016/j.chemosphere.2016.12.042

Ji, X., Liu, T., Liu, J., Li, J., \& Pan, B. (2013). Investigation and Study on Water Quality and Pollution Condition in Lake Xingkai of China. Environmental Monitoring in China (In Chinese, with English abstract). 29(6):79-84.

King, K. W., Williams, M. R., Macrae, M. L., Fausey, N. R., Frankenberger, J., Smith, D. R., Kleinman, P. J. A., \& Brown, L. C. (2015). Phosphorus Transport in Agricultural Subsurface Drainage: A Review. Journal of Environmental Quality, 44(2), 467-485. https://doi.org/10.2134/jeq2014.04.0163

Li, B.G. (2019). Soil science and life (The $14^{\text {th }}$ version)). Science press, Beijing.

Li, M., Hu, Z., Zhu, X., \& Zhou, G. (2015). Risk of phosphorus leaching from phosphorus-enriched soils in the Dianchi catchment, Southwestern China. Environmental Science and Pollution Research, 22(11), 8460-8470. https://doi.org/10.1007/s11356-014-4008-z

LI, W.-X., ZHANG, X.-X., WU, B., SUN, S.-L., CHEN, Y.-S., PAN, W.-Y., ZHAO, D.-Y., \& CHENG, S.-P. (2008). A Comparative Analysis of Environmental Quality Assessment Methods for Heavy Metal-Contaminated Soils. Pedosphere, 18(3), 344-352. https://doi.org/10.1016/s1002-0160(08)60024-7

Lu, R.K. 1999. Analytical Methods of Soil Agrochemistry. Chinese Agriculture Science and Technology Press, Beijing.

Murphy, J., and J.P. Riley. (1962). A modified single solution method for the determination of phosphate in natural waters. Anal Chim Acta 21:11-22.

Piao, D., \& Wang, P. (2011). Environmental conditions and the protection countermeasures for waters of Lake Xingkai. J. Lake Sci. (In Chinese, with English abstract). 23(2):196-202.

Ulén, B., Bechmann, M., Fölster, J., Jarvie, H. P., \& Tunney, H. (2007). Agriculture as a phosphorus source for eutrophication in the north-west European countries, Norway, Sweden, United Kingdom and Ireland: A review. Soil Use and Management, 23(SUPPL. 1), 5-15. https://doi.org/10.1111/j.1475-

2743.2007.00115.x 
Wan, M., Liu, B., \& Jiang, Z. (2013). Analysis of agricultural non-point source pollution load in Xingkai Lake area. Science and Technology Innovation and Application (In Chinese, without English abstract). 20:5-6.

Xie, Z., Li, S., Tang, S., Huang, L., Wang, G., Sun, X., \& Hu, Z. (2019). Phosphorus Leaching from Soil Profiles in Agricultural and Forest Lands Measured by a Cascade Extraction Method. Journal of Environmental Quality, 48(3), 568-578. https://doi.org/10.2134/jeq2018.07.0285

Xie, Z., Yang, X., Sun, X., Huang, L., Li, S., \& Hu, Z. (2021). Effects of biochar application and irrigation rate on the soil phosphorus leaching risk of fluvisol profiles in open vegetable fields. Science of The Total Environment, 147973. https://doi.org/10.1016/j.scitotenv.2021.147973

Yuan, Y., Jiang, M., Liu, X., Yu, H., Otte, M. L., Ma, C., \& Her, Y. G. (2018). Environmental variables influencing phytoplankton communities in hydrologically connected aquatic habitats in the Lake Xingkai basin. Ecological Indicators, 91(April), 1-12. https://doi.org/10.1016/j.ecolind.2018.03.085

Zhao, X. rong, Li, D., Kong, J., \& Lin, Q. mei. (2014). Does biochar addition influence the change points of soil phosphorus leaching? Journal of Integrative Agriculture, 13(3), 499-506.

https://doi.org/10.1016/S2095-3119(13)60705-4

Zhao, X., Zhong, X., Bao, H., Li, H., Li, G., Tuo, D., Lin, Q., \& Brookes, P. C. (2007). Relating soil P concentrations at which $\mathrm{P}$ movement occurs to soil properties in Chinese agricultural soils. Geoderma, 142(3-4), 237-244. https://doi.org/10.1016/j.geoderma.2007.07.012

\section{Figures}

SPOLERC(Soil Phosphorus Leaching Risk Calculator) Input File Path:
Input Sheet Name:

Fan Zhang (email:fanzhang0830@gmail.com)

Zijian Xie (email:zjxie2016@163.com)

\section{Import Data}

Preview
M1 Change Point

M2 Change Point
M1 Risk Evaluation

M2 Risk Evaluation

\section{Figure 1}

The operation interface of the SPOLERC tool for soil P leaching risk calculation 

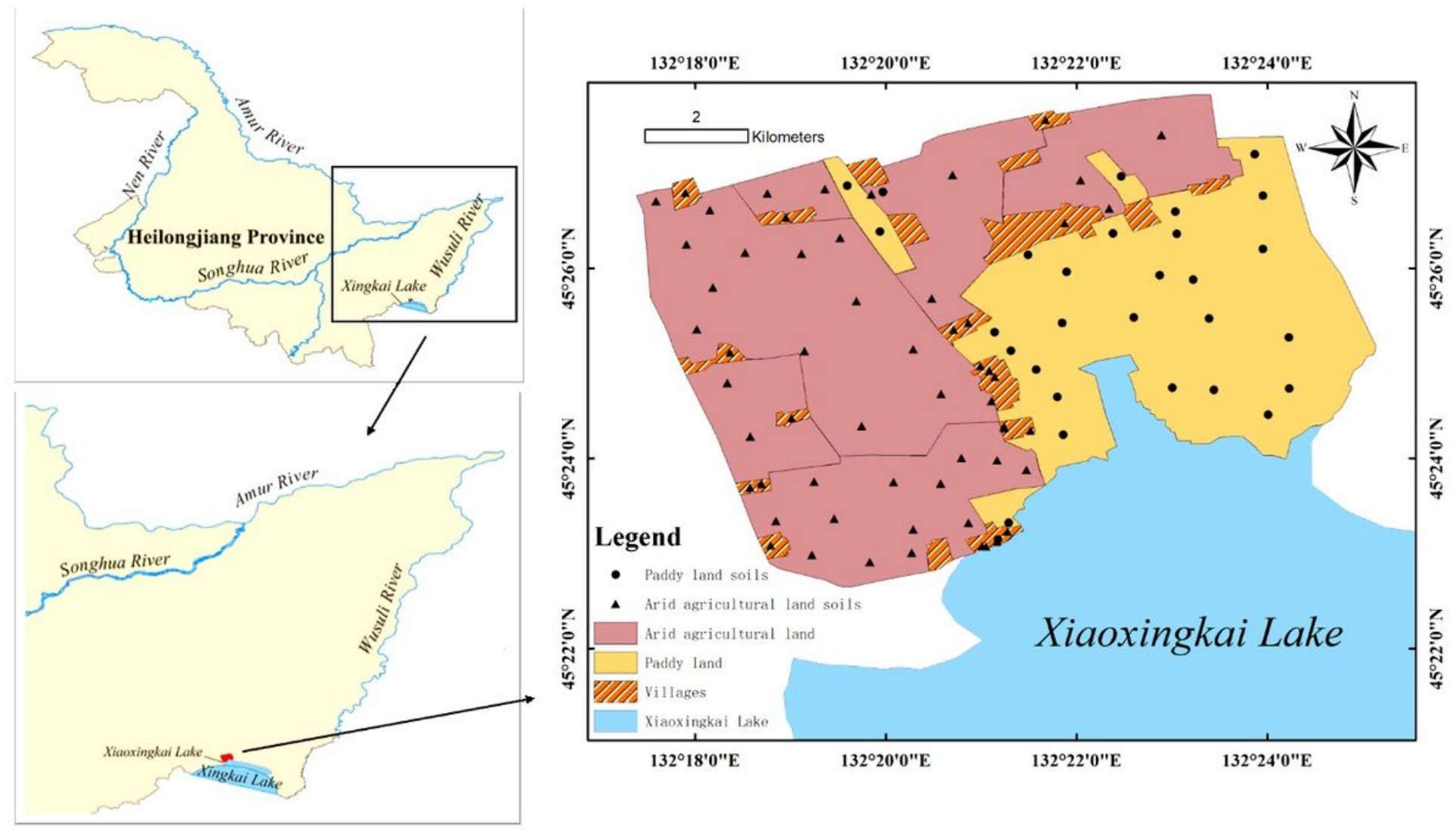

Figure 2

Land uses and sampling sites in the study area 


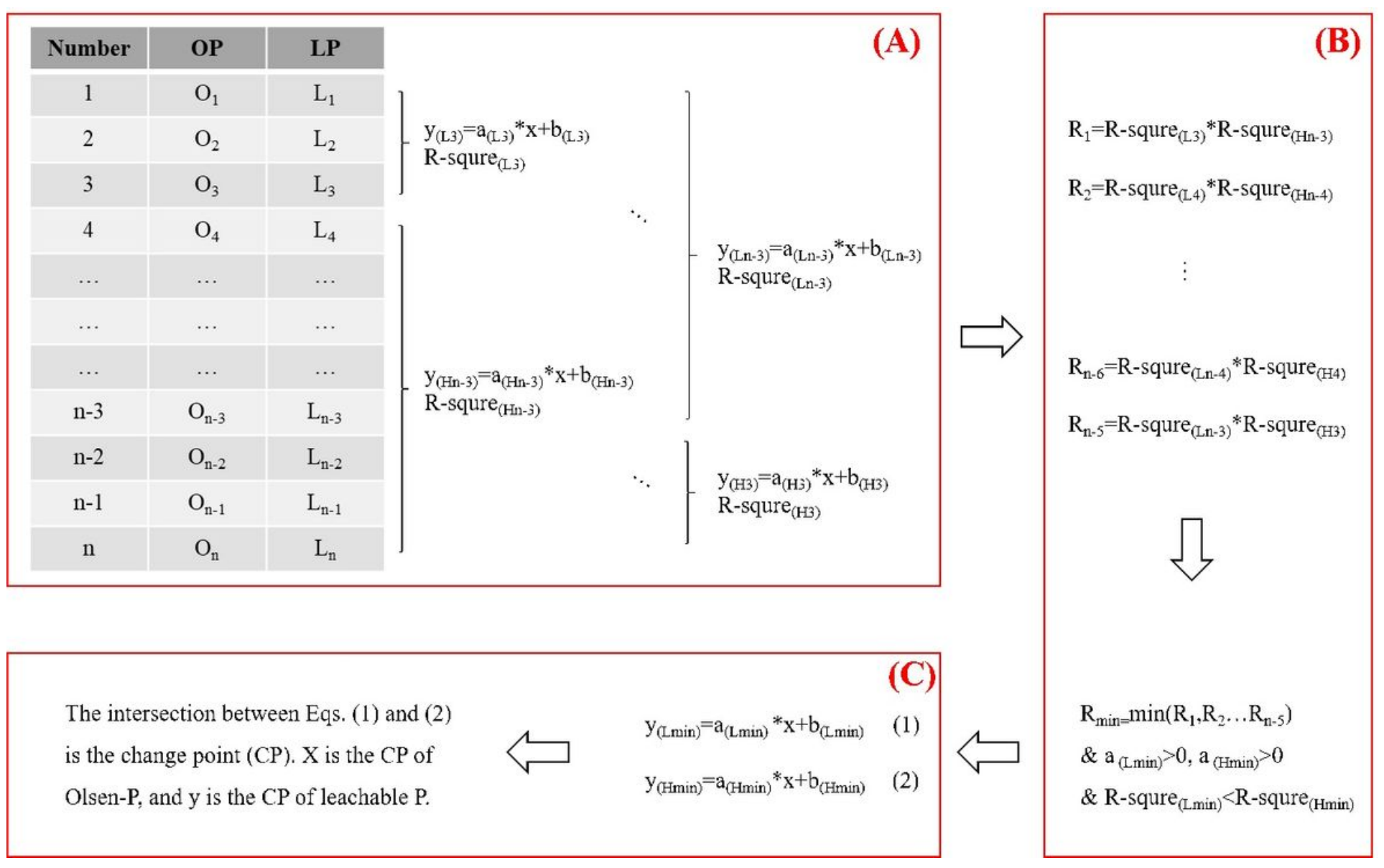

\section{Figure 3}

The calculation process of soil phosphorus leaching change point

a)

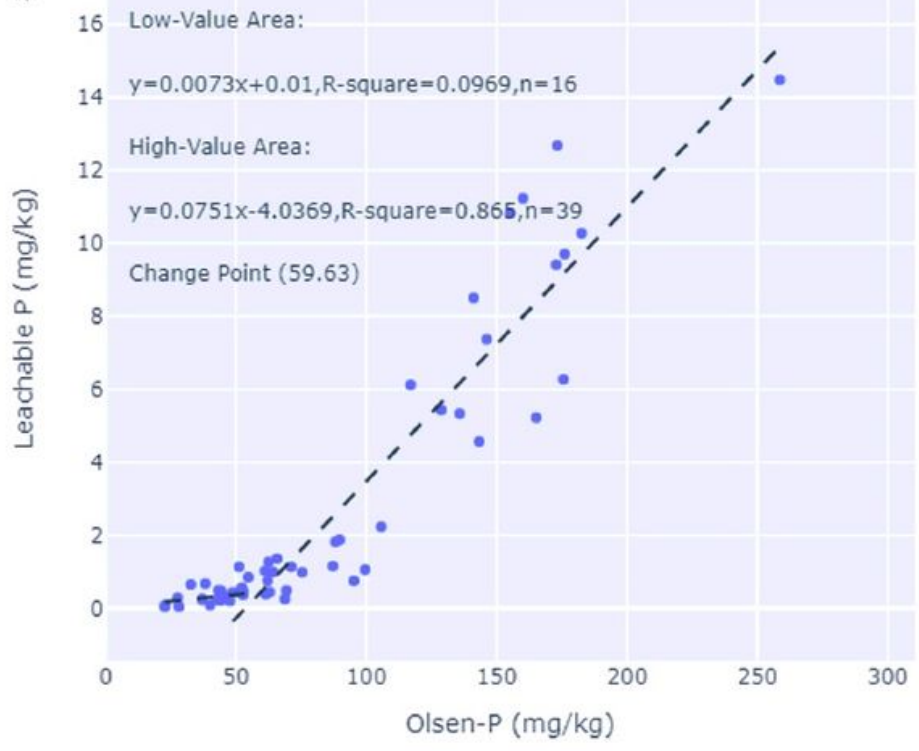

b)

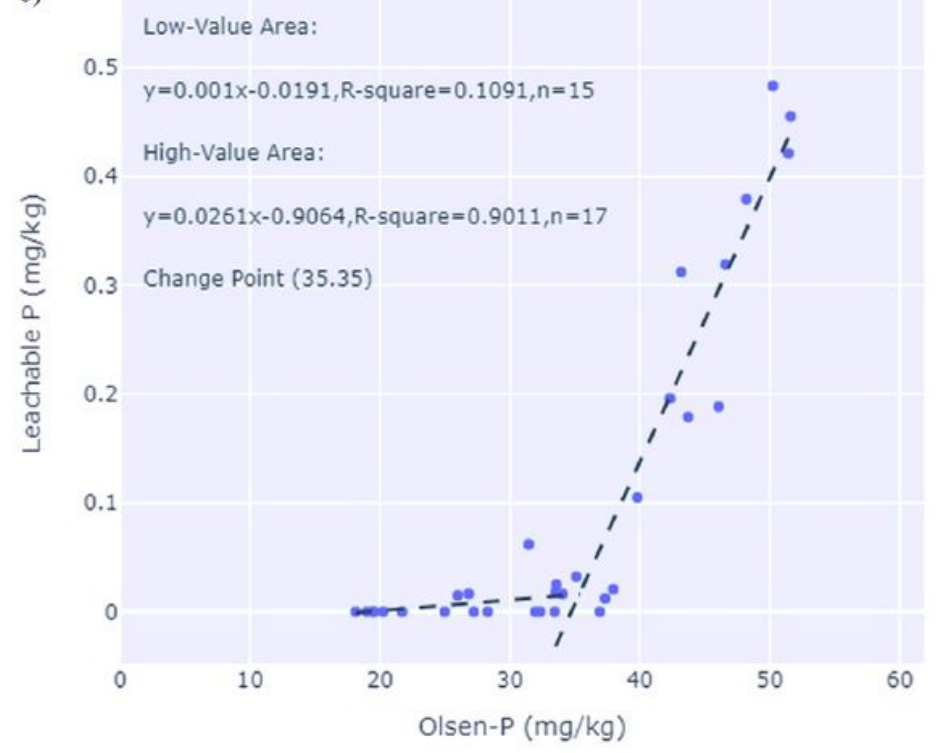

\section{Figure 4}


Soil $\mathrm{P}$ leaching change point based on the relationships between Olsen $\mathrm{P}$ and leachable $\mathrm{P}$ in soils under agricultural land calculated by SPLERC

a)

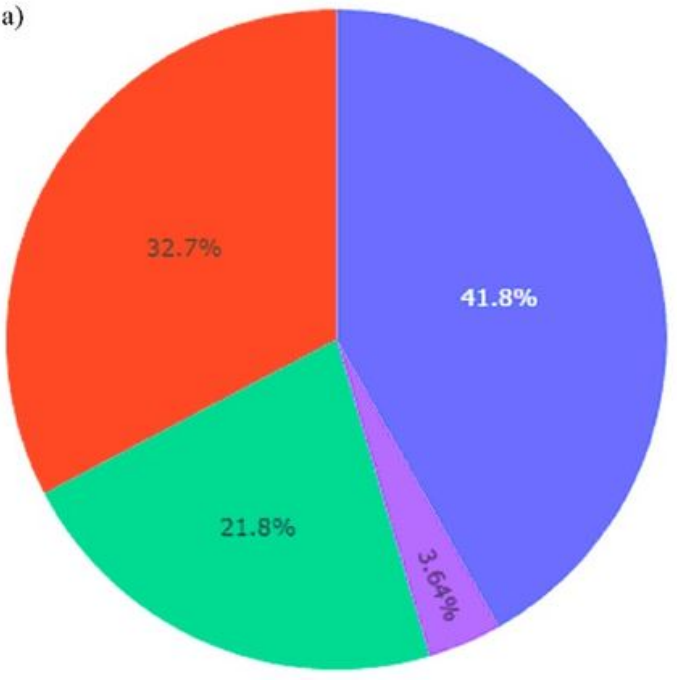

b)

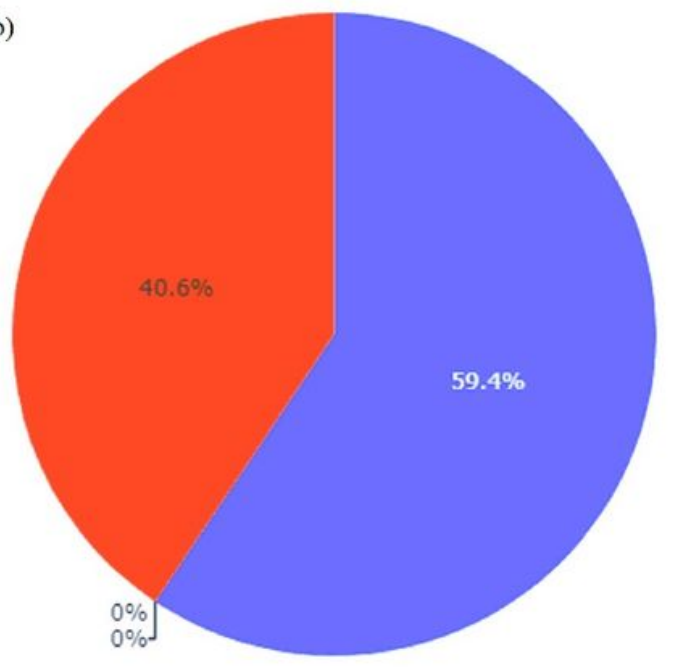

No Risk

Low Risk

Medium Risk

High Risk

\section{Figure 5}

Probability of soil P leaching in arid agricultural soils and paddy land soils measured by SPOLERC 


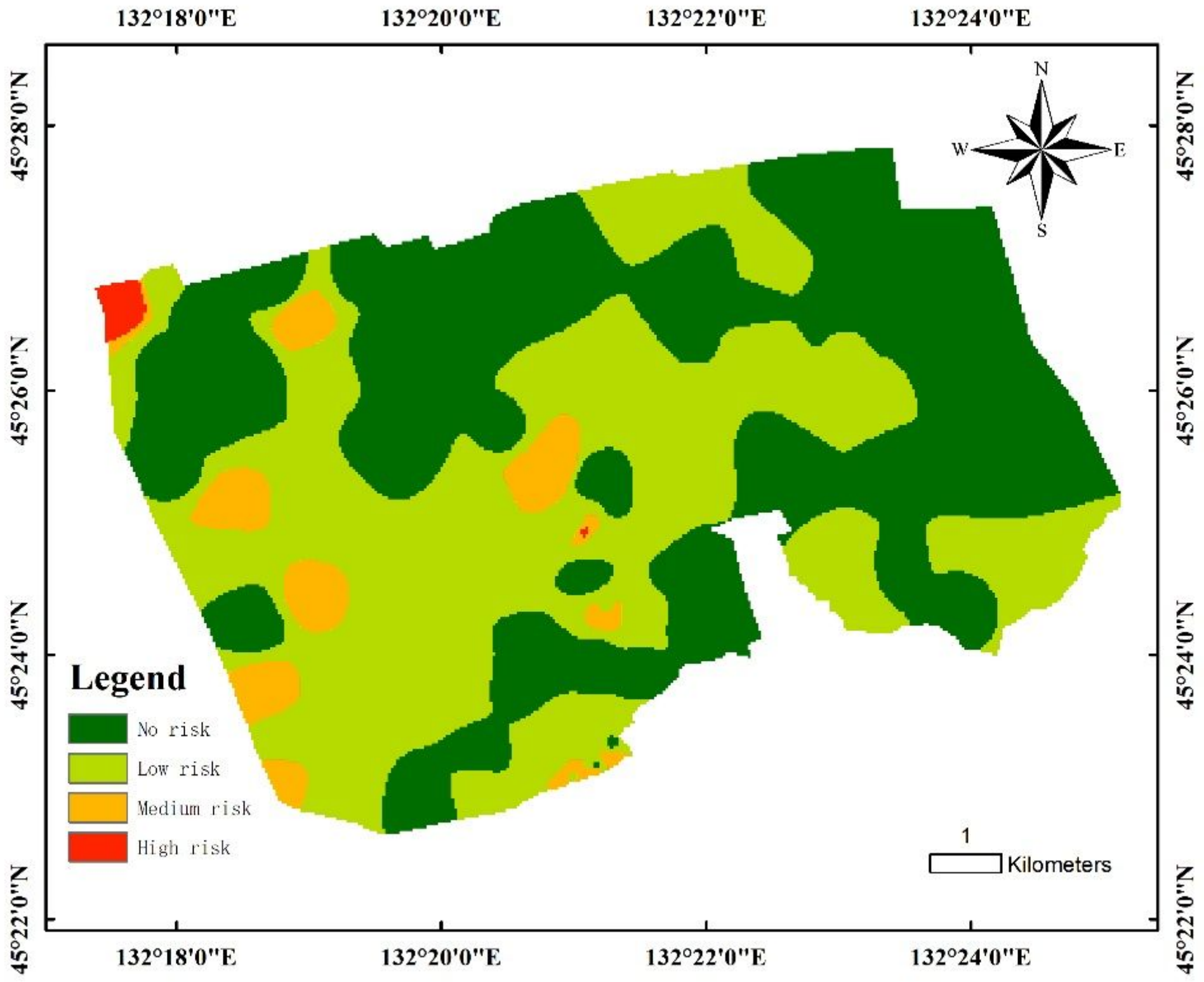

Figure 6

Spatial distribution pattern of soil $\mathrm{P}$ leaching risk in the study area estimated based on soil Olsen $\mathrm{P}$ at sampling sites above the change-point value for $\mathrm{P}$ leaching in agricultural soils

\section{Supplementary Files}

This is a list of supplementary files associated with this preprint. Click to download.

- renamed50915.docx 